
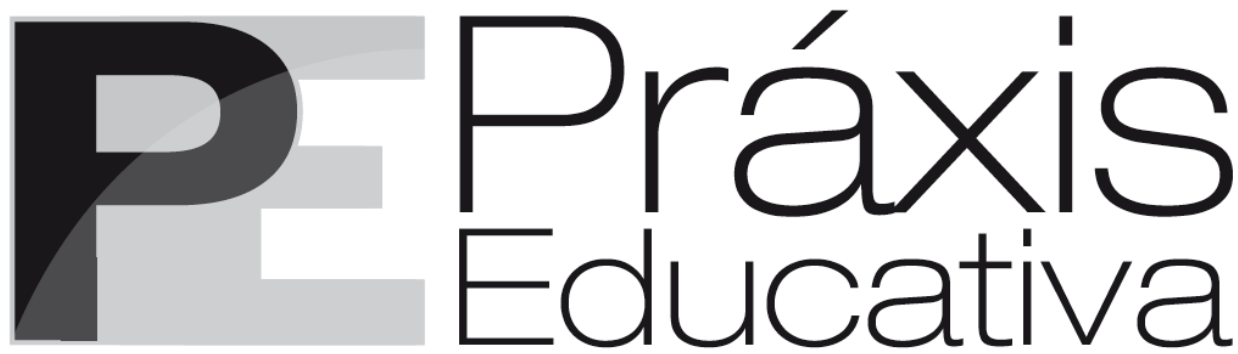

ISSN 1809-4031

eISSN 1809-4309

http://dx.doi.org/10.5212/PraxEduc.v.14n3.010

Resenha

\title{
KRAMER, Sonia; PENA, Alexandra; TOLEDO, Maria Leonor Pio Borges de; BARBOSA, Silvia Néli Falcão (Orgs.). Ética: pesquisa e práticas com crianças na Educação Infantil. Campinas: Papirus, 2019. 254 p.
}

Julia Baumann Campos*

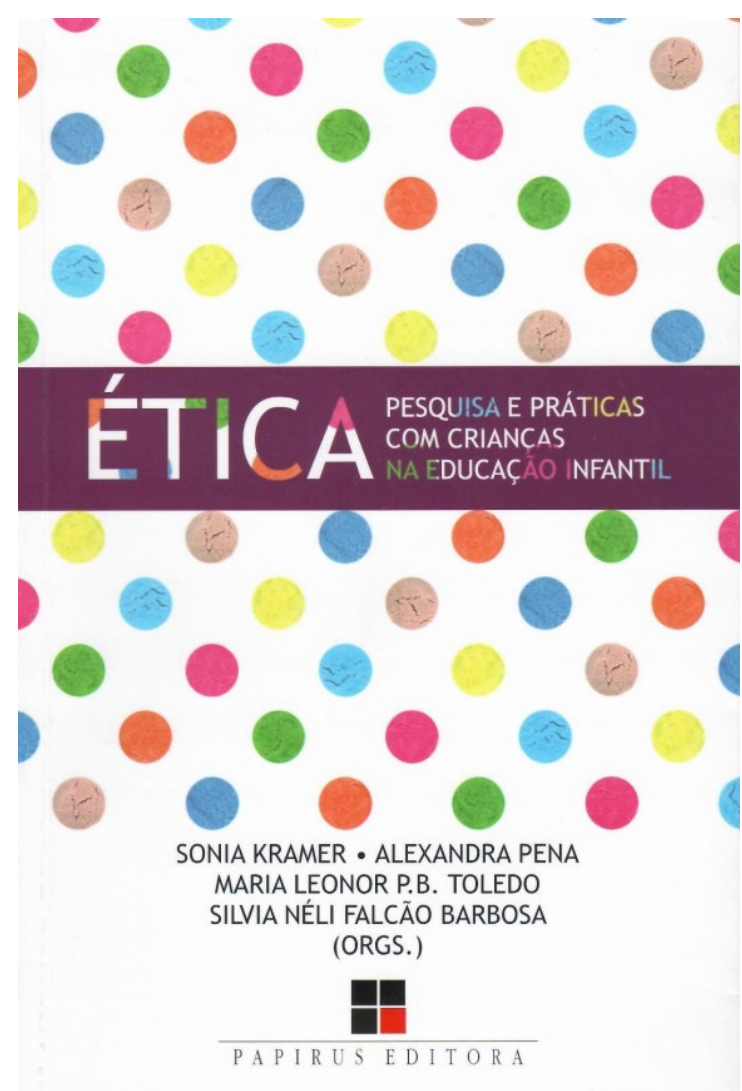

O livro "Ética: pesquisa e práticas com crianças na Educação Infantil” (254 p.), organizado por Sonia Kramer, Alexandra Pena, Maria Leonor Pio Borges de Toledo e Silvia Néli Falcão Barbosa, reúne 12 doze textos que têm como tema central a ética, principalmente, no campo da Educação Infantil. As pesquisas foram realizadas por integrantes do Grupo INFOC (Infância, Formação e Cultura) da PUC-Rio nos últimos 10 anos. O grupo completa, em 2019, 25 anos desde a sua formação.

O livro foi dividido em três grupos: as práticas; as crianças; formação e pesquisa. Todos os eixos são conduzidos pelo tema do engajamento responsável e compromisso com a presença do outro, a responsabilidade com o sujeito pesquisado e o comprometimento com o percurso da pesquisa. A escuta sensível, o olhar atento e o cuidado com as minúcias e desvios que surgem da investigação são visíveis em todos os textos. A entrada no campo, o processo de autorização por parte dos sujeitos da pesquisa em sua participação, o retorno e o cuidado com a devolução dos resultados são apenas alguns dos exemplos de práticas, que revelam um olhar cuidadoso com as histórias e interações existentes nas pesquisas, as tornando coerentes com as contribuições de Martin Buber, autor muito presente no livro.

* Julia Baumann Campos é doutoranda do Programa de Pós-Graduação em Educação da Pontifícia Universidade Católica do Rio de Janeiro. E-mail: <juliabaumann8@gmail.com>. ORCID: https:/ /orcid.org/0000-0001-7094-5788

Práxis Educativa, Ponta Grossa, v. 14, n. 3, p. 997-1003, set./dez. 2019 Disponível em: <http://www.revistas2.uepg.br/index.php/praxiseducativa> 
KRAMER, S.; PENA, A.; TOLEDO, L. P. B.; BARBOSA, S. N. F. (Orgs.). Ética: pesquisa e práticas...

Para Buber (1977), só há responsabilidade onde há o responder verdadeiro diante dos acontecimentos do cotidiano. Além da postura responsável é preciso que o pesquisador esteja presente. Estar presente supõe que os sujeitos estejam envolvidos, com compromisso, no instante atual, que estejam abertos para o outro. A presença é uma forma de apreensão do mundo para além da observação. Estar diante de seres humanos requer a construção de um vínculo de confiança, de uma postura de reconhecimento do outro e de sua alteridade. Os pesquisadores desta obra estão, de fato, presentes.

No primeiro eixo, as práticas estão em destaque. Cada autora buscou compreendê-las observando e refletindo de que forma essas práticas estão sendo oferecidas às crianças. Os espaços percorridos por elas no dia a dia, a avaliação do que aprendem, a escuta sensível ao que pensam e a observação das manifestações dos bebês e sua relação com os livros são os temas dos quatro textos, que compõem o primeiro eixo.

Maria Leonor P. B. de Toledo apresenta, em seu texto, "Pátios de escolas de Educação Infantil: a dimensão ética das políticas", os resultados de sua tese de doutorado. A pesquisa buscou compreender as características físicas dos pátios relacionando-as às concepções de infância, conhecimento e relação entre ser humano e natureza; como são usados por crianças e adultos e; por último, os pontos de aproximação e de distanciamento entre as condições dos pátios e os documentos brasileiros relevantes que orientam este tema. Foram pesquisados pátios em nove instituições de Educação Infantil no Estado do Rio de Janeiro. A autora utilizou o recurso fotográfico para pensar na qualidade dos espaços e analisar as práticas existentes nesses. Após visitá-los, fotografar, analisar, refletir sobre os caminhos percorridos nesses pátios e dialogar com autores e documentos orientadores, a autora afirma que é preciso mudar essa situação. As crianças precisam fazer parte da elaboração e da organização desses espaços. É necessário valorizar as significações que elas trazem em suas interações e práticas. Além das crianças, a autora defende a participação de profissionais da educação e de arquitetos na elaboração de um planejamento para os espaços. Dessa forma, será possível aliar as características físicas dos pátios escolares às interações potentes que acontecem nesses lugares.

"Avaliação na Educação Infantil como compromisso ético - o que se espera que as crianças aprendam?" é um recorte da pesquisa de doutorado de Marina Castro e Souza. O artigo discute a avaliação na creche, tema que vem ganhando destaque por conta da ampliação do acesso das crianças em creches e pré-escolas. Segundo a autora, a discussão da avaliação traz, de forma subjacente, uma reflexão sobre qualidade (p.28). A concepção de qualidade precisa ser considerada como um termo polissêmico, segundo a autora, como produção da política (p. 28), a pesquisa trabalha em direção a uma perspectiva humana, em que são valorizadas as histórias dos sujeitos, propostas e instituições. Foram realizadas observações em um Espaço de Desenvolvimento Infantil (EDI) na cidade do Rio de Janeiro, que atende crianças entre três meses e cinco anos. A autora construiu categorias a partir das observações de interações entre adultos e crianças e as analisou em diálogo com as contribuições de Mikhail Bakhtin. Ao final da pesquisa fica clara a existência, ainda, de uma perspectiva de avaliação desenvolvimentista, que se articula às ideias de controle e de disciplina. É necessário superar essa perspectiva e defender uma aprendizagem crítica, reflexiva e construída de forma ativa pelos sujeitos.

"A pesquisa também é das crianças: o retorno ao campo como resposta responsável", de Gabriela Scramingnon, apresenta a etapa de retorno ao campo e devolução dos resultados da pesquisa com crianças. O texto se origina a partir de sua tese de doutorado, que buscou compreender o que falam crianças de seis a dez anos sobre a experiência de ser criança no mundo contemporâneo e como ocorrem as relações entre elas e os adultos. A pesquisa foi realizada em uma instituição não governamental sem fins lucrativos, em 2015 e 2016, e teve como estratégias

Práxis Educativa, Ponta Grossa, v. 14, n. 3, p. 997-1003, set./dez. 2019 Disponível em: <http://www.revistas2.uepg.br/index.php/praxiseducativa $>$ 
metodológicas entrevistas coletivas com crianças de seis a dez anos no formato de um jornal, além de observações de suas interações. A autora buscou fazer uma pesquisa com as crianças e não sobre elas, revelando uma escuta sensível, valorizando suas narrativas e histórias e, as considerando ativas e participantes nos grupos em que se inserem.

O último texto deste eixo é de Nazareth Salutto de Mattos que escreve, de forma delicada, sobre a relação dos bebês com o mundo ao seu redor. Bebês e livros: a relação como princípio é parte de sua pesquisa de doutorado e aborda o encontro de bebês com livros, dialogando com os autores Martin Buber e Donald Winnicott. A pesquisa foi desenvolvida com a participação de vinte e um bebês entre quatro e dezoito meses, três educadores, uma pesquisadora e uma bolsista de iniciação científica. Ao propor a articulação entre livros e bebês, a autora se vê provocada a refletir sobre o bebê e sua imersão na cultura. Ao se debruçar sobre a relação entre bebês e livros, a autora se dedica às marcas que constituem o bebê, suas relações com os adultos e as práticas que possuem uma relação respeitosa, acolhedora e que reconhecem as singularidades dos bebês. Ao agir sobre os espaços e materiais, o bebê os cria (p. 64). À medida que o bebê se relaciona com o mundo, ele cria a sua própria realidade subjetiva, reconhece o mundo a partir de suas relações, de seu contato com o outro. Então, compreender e dar sentido ao mundo, para os bebês, passa por estar ao lado, com o outro e, na perspectiva da relação como princípio, juntos, tecerem a realidade da qual participam (p. 64). É necessária uma prática cuidadosa, delicada, sutil e respeitosa para, assim, existir a possibilidade de um encontro que produza sentido entre bebês e livros.

No segundo eixo, as crianças estão no foco. Nessa parte do livro, três textos revelam as perspectivas das crianças em instituições de Educação Infantil sobre o espaço, o currículo e as interações entre crianças e adultos e crianças e seus pares. São pesquisas que apresentam escuta e olhares cuidadosos, tomando sempre a criança como ator social, ativo em suas relações e sujeito competente na construção de sentidos no mundo.

Marta Nídia Varella Gomes coloca as crianças no centro e dá visibilidade ao que pensam sobre o currículo do qual são sujeitos nas instituições de Educação Infantil. Isso é o que eu não sei responder: o currículo nas palavras das crianças foi escrito a partir da tese de doutorado: Currículo da Educação Infantil e Datas Comemorativas: o que dizem profissionais e crianças, escrito pela mesma autora em diálogo com os autores Mikhail Bakhtin, Walter Benjamin, Manuel Sarmento e Jens Qvortrup. Foram observadas crianças em turmas de pré-escola em duas instituições públicas na região metropolitana do Rio de Janeiro. As observações se davam no cotidiano da instituição e, durante essas observações, as crianças foram ouvidas e foi possível enxergar um currículo pautado na sucessão de datas comemorativas. Elas, com frequência, expressavam estar cumprindo uma ordem da professora parecendo não conseguir compreender o sentido daquela atividade. A criança, considerada sujeito pleno, capaz de significar e ressignificar acontecimentos e encontros, competente para descobrir e pesquisar fatos de acordo com sua curiosidade e desejo é posta, então, no lugar de, apenas, cumprir orientações. A autora defende um currículo que seja coerente com os desejos, demandas e interesses das crianças, como atitude ética que precisa prevalecer nas instituições de Educação Infantil.

Conbecer os espaços com as crianças: escuta como postura ética foi escrito por Liana Garcia Castro e articula as perspectivas das crianças ao espaço que percorrem, em seu cotidiano, em uma creche da rede pública de um município da Região Metropolitana do Rio de Janeiro. A partir de sua dissertação de mestrado, a autora busca responder, dialogando com as crianças: o que seus olhares $e$ perspectivas narram sobre o que veem e registram do espaço por elas frequentado e vivido cotidianamente? (p. 83). O registro fotográfico como estratégia metodológica privilegiada permitiu que as crianças mostrassem o que viam no cotidiano da instituição. A autora realizou uma oficina de fotografia em dois momentos: no primeiro, as crianças fotografaram os espaços escolhidos e, no segundo,

Práxis Educativa, Ponta Grossa, v. 14, n. 3, p. 997-1003, set./dez. 2019 Disponível em: <http://www.revistas2.uepg.br/index.php/praxiseducativa > 
KRAMER, S.; PENA, A.; TOLEDO, L. P. B.; BARBOSA, S. N. F. (Orgs.). Ética: pesquisa e práticas...

viam suas fotos e contavam sobre o que olhavam. A pesquisa ocorreu no entrecruzamento dos estudos da Psicologia Histórico-Cultural formulados por Vigotski, da Sociologia da Infância partindo de Corsaro, Ferreira e Sarmento e da Filosofia do Diálogo de Buber. Ao final do texto, a pesquisadora defende a necessidade de considerar as possibilidades de ações das crianças nos espaços escolares e que sejam construídas, em diálogo com os adultos, compreensões e saídas para os problemas.

Anelise Monteiro do Nascimento em seu texto “Gostaram da bistória? Muito bem!”: ser criança $e$ ser aluno na Educação Infantil busca responder algumas questões acerca do impacto da escolarização sobre a experiência de infância de crianças da Educação Infantil: o que dizem sobre frequentar uma escola de Educaşão Infantil? Como se veem dentro dessa instituição? (p. 100). A pesquisa procurou compreender as formas como as crianças se apropriam das práticas sociais que lhes são impostas. Os estudos da filosofia, principalmente, o trabalho de Walter Benjamin; a Sociologia da Infância e, a análise do contexto político que inclui as práticas de institucionalização das crianças no Brasil, contribuíram para o percurso da pesquisa. O estudo foi construído a partir de observações em vinte e uma instituições de Educação Infantil da rede municipal do Rio de Janeiro e fez parte da pesquisa: "Crianças e adultos em diferentes contextos: a infância, a cultura contemporânea e a educação" realizada pelo Grupo INFOC (Infância, Formação e Cultura) de 2005 a 2008. A autora mostra como a criança, neste espaço de escolarização, constrói o ofício de criança e o ofício de aluno em suas interações. Ao final, a pesquisadora afirma que estudos como esses assumem uma dimensão ética da pesquisa, abrangem a qualidade das práticas e o envolvimento e compromisso do pesquisador com os sujeitos da pesquisa.

O terceiro e último eixo reúne textos que têm em comum os temas da formação e pesquisa. $\mathrm{Na}$ parte final desta obra, os autores se dedicam ao ato de pesquisar e suas contribuições para a formação de profissionais da área da Educação. A reflexão sobre o tema da ética aparece novamente com força e é pensado, em diálogo, com a formação de professores; a formação de pesquisadores; e a autoria e a visibilidade das crianças participantes das pesquisas, além da garantia da construção de sentidos por elas neste processo.

Alexandra Pena em seu texto Diálogo, encontro e agir ético: a contribuição das histórias de vida para a formação de professores traz para a cena o tema da formação de professores. A pesquisa contou com as histórias de vida de dez educadoras de creches e pré-escolas da Baixada Fluminense do Rio de Janeiro. Escutar as narrativas de dez educadoras demonstra a sensibilidade e cuidado da pesquisa com suas histórias e memórias e faz com que essas educadoras entendam que suas histórias são importantes, que têm valor e que fazem parte de seu processo de formação. Mikhail Bakhtin, Paulo Freire e Martin Buber contribuem para o desenvolvimento da pesquisa. Ao final, a autora defende uma formação que valorize as histórias e as experiências de cada um, que articule o conhecimento intelectual e conhecimento de si pensando na relação dialógica entre os sujeitos, a entrega e a inteireza em sua formação. É necessário romper com uma concepção de formação como transmissão de conteúdos e técnicas [...] Se, ao contrário, compreendemos que a educação é concebida como prática social que tem como finalidade a formação humana, ela pressupõe a relação dialógica (p. 123).

"Deixa eu escrever meu nome aî?": - o assentimento como estratégia ética e metodológica na pesquisa com crianças foi escrito pela autora Silvia Néli Falcão Barbosa e debate a respeito do desafio de garantir às crianças o seu lugar no processo de construção de sentidos. O texto partiu da pesquisa de doutorado da autora e foi desenvolvida em um município da Baixada Fluminense. Durante a pesquisa, foram observadas duas turmas de crianças de três anos em duas creches, uma pública e uma comunitária. O texto aborda o tema do processo de institucionalização, a qualidade das relações cotidianas e é um convite para refletir acerca de uma metodologia, que valorize os sentidos trazidos pelas crianças e que considere o lugar de alteridade que ocupam. Walter

Práxis Educativa, Ponta Grossa, v. 14, n. 3, p. 997-1003, set./dez. 2019 Disponível em: <http://www.revistas2.uepg.br/index.php/praxiseducativa > 
Benjamin e Mikhail Bakhtin contribuem com o percurso da pesquisa e, junto da autora, pensam a respeito do lugar de visibilidade que precisa ser garantido para as crianças e os adultos que participam das pesquisas. Sustentar as crianças e os adultos como sujeitos da pesquisa, que têm voz é assumir que os mesmos têm algo a dizerer, a criticar, a enunciar. Ambos têm opiniões, ideias, experiências a compartilhar entre si (p. 138).

Maria Fernanda Rezende Nunes apresenta em: Uma leitura ética da política de Educação Infantil sobre os direitos das crianças temas que dialogam com os direitos das crianças no campo da Educação Infantil. O texto foi produzido a partir de uma releitura de pesquisas dos grupos INFOC/PUC-Rio (Infância, Formação e Cultura) e EIPP/UNIRIO (Educação Infantil e Políticas Públicas), que possuem uma parceria desde 2005, além de estudos de pós-graduandos orientados pela autora. Os grupos têm como principais temas de pesquisa a formação de professores, a infância e a cultura. A autora aborda o tema dos direitos das crianças à educação, a partir da perspectiva do município do Rio de Janeiro e da perspectiva das próprias crianças abrindo, desta forma, espaço para as narrativas, desejos e experiências, tornando as crianças produtoras e autoras de suas histórias.

Aprender a ser: o encontro do Eu pesquisador e o Eu professor na pesquisa com histórias de vida foi escrito por Alexandra Pena, Amanda da Silva, Pedro Lontra e Rafaela Trugilho e parte das inquietações que surgiram durante as observações nas escolas visitadas na pesquisa: "Linguagem e rememoração: crianças, famílias, professores/as e suas histórias", ainda em andamento, do grupo INFOC. Tornar-se pesquisador e entrar em contato com as histórias de vida dos sujeitos pesquisados mobilizou grandes questões por parte dos autores do texto. Como agir? Qual o nosso papel? Como pesquisar? São alguns exemplos de dúvidas que surgiram e motivaram a escrita do texto. Fazer pesquisa com essa metodologia requer escuta atenta e sensível do pesquisador que se sente convocado a aprender, refletir e ressignificar a condição de professor e pesquisador em processo de formação. O conhecimento na pesquisa em Ciências Humanas ocorre na relação entre pesquisador e sujeito pesquisado. No contexto da pesquisa em Ciências Humanas, em que sujeitos e contextos são vivos e dinâmicos, todos nos tornamos educandos na arte de fazer pesquisa, tarefa fundamental também para o professor (p. 154). Encontrar o outro a partir das dúvidas, das angústias e das inquietações é relevante para a formação docente e humana, pensando que os autores do texto são pesquisadores e professores. Tornar-se pesquisador requer o outro (p. 154).

Encerrando a obra, Sonia Kramer apresenta, em seu texto Des/acertos, silêncios e conflitos éticos: o que você faz. com os resultados da sua pesquisa?, o debate sobre as questões éticas na pesquisa em geral e na pesquisa com crianças em particular. O texto foi organizado em duas partes: a primeira apresenta as questões relativas à autoria e autorização; a segunda discorre sobre os conflitos relativos à entrada e saída do campo, existentes entre instituições e pesquisadores. O texto traz questionamentos importantes para o contexto atual: o que você faz com o seu conhecimento? Onde você está? e a escrita do texto acontece em um momento de grande exigência burocrática para entrar na pesquisa, árduo esforço para a possibilidade de investigação. A autora finaliza o texto afirmando que a ética do pesquisador deve prevalecer sobre as exigências burocráticas e que as manifestações infantis nas pesquisas com crianças devem ser acolhidas, respeitadas, valorizadas. É compromisso político, científico e ético compartilhar o que falam e mostram as crianças, como se expressam e se relacionam, o que desejam e o que produzem. É compromisso do pesquisador a devolução dos resultados e a responsabilidade com o que aparece nas pesquisas. A indiferença é inaceitável (p. 175).

O livro é uma forma de devolução dos resultados das pesquisas aqui apresentadas. Registrar esses resultados e compartilhar essa obra é uma maneira de devolver o que foi aprendido pelos pesquisadores e, assim, partilhar os questionamentos que surgem a partir do

Práxis Educativa, Ponta Grossa, v. 14, n. 3, p. 997-1003, set./dez. 2019 Disponível em: <http://www.revistas2.uepg.br/index.php/praxiseducativa > 
KRAMER, S.; PENA, A.; TOLEDO, L. P. B.; BARBOSA, S. N. F. (Orgs.). Ética: pesquisa e práticas...

campo, das narrativas e das reflexões. É indicada a leitura, principalmente, para a formação continuada de profissionais da Educação em geral e, também, para pesquisadores da área das Ciências Humanas.

A compreensão ativa, em uma pesquisa, envolve assumir um pensamento, ser responsável por esse, torná-lo um ato, um pensamento não indiferente, um pensamento verdadeiramente ético. A pesquisa em Ciências Humanas é ato de "debruçar-se subjetivamente sobre a produção subjetiva de um outro" (PEREIRA, 2012, p. 64), portanto, seu compromisso social e político e a relação pesquisador-pesquisado precisam ser sensíveis, comprometidos e responsáveis. Assumir responsabilidade na e com a pesquisa é assumir a presença do outro, tendo respeito por ele como pessoa e cidadão. É ter a consciência que o ato de pesquisar não é neutro (TEIXEIRA; OLIVEIRA, 2010).

O rigor, a clareza e os critérios aparecem como aspectos de grande relevância no campo da pesquisa. No entanto, utilizar regras, ser cauteloso nos procedimentos e rigoroso com as etapas da pesquisa não se relaciona a uma postura mecânica. Há também flexibilidade, dinamismo, abertura, surpresas, desvios, valorização dos desejos do sujeito que está sendo pesquisado e dos rumos que se entrecruzam no processo da pesquisa. Há respeito pelas diferentes realidades e experiências que aparecem, fendas para a construção de novas ideias, imprevisibilidade e cuidado com a dimensão humana.

Fazer pesquisa não é um ato puramente racional, automático, neutro e prescritivo. A atitude de um pesquisador envolve a troca com o sujeito da pesquisa e contribui para a sua formação humana. A pesquisa envolve a conexão com o presente e com a atualidade, transformações no planejamento e, principalmente, a pesquisa envolve a responsabilidade com o outro.

De modo mais amplo, o livro "Ética: pesquisa e práticas com crianças na Educação Infantil" vem contribuir para a ampliação do debate sobre ética na pesquisa em educação, que vem sendo estimulado em diversas ações da Anped (ANPED, 2019), bem como em livros (SANTOS; KARNOPP, 2017; BROOKS; TE RIELE; MAGUIRE, 2017) e outras publicações recentes (CARVALHO, 2017; MAINARDES, 2017; NUNES, 2017; DE LA FARE; SAVI NETO, 2019).

\section{Referências}

ANPEd. Comissão de Ética. Ética e pesquisa em Educação: subsídios - v. 1. Rio de Janeiro: Anped, 2019. Disponível em: <http://www.anped.org.br/sites/default/files/images/etica_e_pesquisa_em_educacao__isbn_final.pdf>. Acesso em: 28 ago. 2019.

BROOKS, R.; TE RIELE, K.; MAGUIRE, M. Ética e pesquisa em Educação. Ponta Grossa: Editora UEPG, 2017.

BUBER, M. Eu e tu. Tradução e introdução de Newton Aquiles von Zuben. São Paulo: Moraes, 1977.

CARVALHO, I. C. M. Ética e pesquisa em Educação: o necessário diálogo internacional. Práxis Educativa, Ponta Grossa, v. 13, n. 1, p. 1-10, jan./abr. 2018. DOI: http://dx.doi.org/10.5212/PraxEduc.v.13i1.0009 
DE LA FARE, M.; SAVI NETO, P. S. A regulação da conduta dos pesquisadores na ciência brasileira: um problema de pesquisa ou um problema para a pesquisa em educação? Práxis Educativa, Ponta Grossa, v. 14, n. 1, p. 319-332, jan./abr. 2019. DOI: http://dx.doi.org/10.5212/PraxEduc.v.14n1.017

MAINARDES, J. A ética na pesquisa em educação: panorama e desafios pós-Resolução CNS n ${ }^{\circ}$ 510/2016. Educação, Porto Alegre, v. 40, n. 2, p. 150-173, jan./abr. 2017. DOI: https://doi.org/10.15448/1981-2582.2017.2.26878

NUNES, J. B. C. Formação para a ética em pesquisa: um olhar para os programas de pósgraduação em Educação. Educação, Porto Alegre, v. 40, n. 2, p. 183-191, jan./abr. 2017. DOI: https://doi.org/10.15448/1981-2582.2017.2.26889

PEREIRA, R. M. R. Pesquisa com crianças. In: PEREIRA, R. M. R. Infância em pesquisa. Rio de Janeiro: NAU Editora, 2012. p. 59-85.

SANTOS, L. H. S.; KARNOPP, L. B. (Orgs.). Ética e pesquisa em Educação: questões e proposições às ciências humanas e sociais. Porto Alegre: Editora de UFRGS, 2017.

TEIXEIRA, E.; OLIVEIRA, I. A. de. Cuidados éticos na pesquisa. In: MARCONDES, M. I.; TEIXEIRA, E.; OLIVEIRA, I. A. de. Metodologias e técnicas de pesquisa em educação. Belém: EDUEPA, 2010. p. 9-24. 